\title{
SUPERAÇÃO DA ALIENAÇÃO DOS ALUNOS PARA A REALIZAÇÃo DA LEITURA CRÍTICA
}

\author{
LA SUPERACIÓN DE LA ALIENACIÓN DE LOS ESTUDIANTES PARA LA \\ REALIZACIÓN DE LA LECTURA CRÍTICA
}

DISPOSITION OF OVERCOMING STUDENTS FOR CRITICAL READING

\author{
Rosangela Miola GALVÃO ${ }^{1}$ \\ Sandra Aparecida Pires FRANCO ${ }^{2}$
}

RESUMO: Objetiva-se neste artigo apresentar as possibilidades de uma prática educativa que tem como foco o formar alunos da Educação Básica em leitores críticos. Para tanto, compreender os conceitos de alienação e de linguagem sob a ótica do Materialismo Histórico e Dialético e da Teoria Histórico-Cultural foram essenciais para perceber como os alunos de um $7^{\circ}$ ano são capazes de superar este paradigma que contribui para a leitura ingênua dos textos trabalhados em sala de aula. Tratou-se de um estudo qualitativo de revisão bibliográfica em união com a prática dialética com alunos em uma escola pública situada no norte do Estado de Paraná. Como metodologia foram desenvolvidas doze aulas com material diversificado nas quais a mediação do docente buscou contemplar forma e conteúdo de maneira que ocorresse a desconstrução do conceito de herói fíctício representado ao final pela arte do poema haicai. $\mathrm{O}$ uso do instrumento celular e whatsapp foram importantes para o desenvolvimento do senso poético. Busca-se, portanto, demonstrar as contribuições do materialismo histórico e dialético para a prática docente e o desenvolvimento humano. As considerações dos teóricos permitem constatar que a linguagem contribui para o desenvolvimento das funções psíquicas superiores no homem e que a alienação dos sujeitos na sociedade atual afeta consideravelmente a interpretação dos alunos e, consequentemente, a formação para a leitura crítica, que pode ser superada com o uso de uma corrente teórica consciente.

PALAVRAS-CHAVE: Alienação. Linguagem. Leitura Crítica.

RESUMEN: El Objetivo en este artículo es presentar las posibilidades de una práctica educativa que se centra en la formación de estudiantes de Educación Básica en lectores críticos. Por lo tanto, la comprensión de los conceptos de alienación y el lenguaje desde la perspectiva del materialismo histórico y dialéctico y la teoría histórico-cultural son esenciales para ver cómo los estudiantes de $7^{\circ}$ grado son capaces de superar este paradigma que contribuye a la lectura ingenua de los textos trabajado en el aula. Este fue un estudio cualitativo de la revisión de la literatura en unión con la práctica dialéctica con

${ }^{1}$ Universidade Estadual de Londrina (Uel), Londrina - PR - Brasil. Mestrado em Educação. Gestora de instituição de ensino público do Paraná. E-mail: rmgalvao2012letras@gmail.com.

${ }^{2}$ Universidade Estadual de Londrina (Uel), Londrina - PR - Brasil. Professora Adjunta do Departamento de Educação. Pós-doutorado em Educação pela Unesp - Marília. E-mail: sandrafranco26@ hotmail.com.

RPGE - Revista on line de Política e Gestão Educacional, v Araraquara, v.21, n. esp.3, p. 1703-1714, dez., 2017. 
los estudiantes en una escuela pública ubicada en el norte del estado de Paraná. La metodología fue desarrollada con doce clases con diversos materiales en los que la mediación del maestro solicita a contemplar la forma y el contenido de lo que le ocurrió a deshacer el concepto de héroe de ficción con el uso del arte de haikai. El uso del instrumento móvil y WhatsApp fueron importantes para el desarrollo del sentido poético. Las actividades muestran las contribuciones del materialismo histórico y dialéctico para la práctica de la enseñanza y el desarrollo humano. Las consideraciones determinan que el lenguaje contribuye al desarrollo de las funciones psíquicas superiores del hombre y de la alienación de los individuos en la sociedad de hoy en día que afecta en gran medida la interpretación de los estudiantes y, en consecuencia, la formación para la lectura crítica, que puede ser superada con el uso de una corriente teórica consciente.

PALABRAS CLAVE: Alienación. Lenguaje. Lectura crítica.

ABSTRACT - This article aims to present the possibilities of an educational practice that focuses on the formation of Basic Education students in critical readers. For this, understand the concepts of alienation and language from the point of view of Historical and Dialectical Materialism and Historical-Cultural Theory was essential to understand how the students of the 7th year are able to overcome this paradigm that contributes to the naive reading of texts worked in the classroom. It was a qualitative study of bibliographic revision in union with the dialectical practice with students in a public school located in the north of the State of Paraná. As methodology, was developed twelve classes with diversified material in which the teacher's mediation sought to contemplate form and content in the way that occurred the deconstruction of the fictitious hero concept represented at the end by the art of the haicai poem. The use of the cell phone instrument and Whatsapp were important for the development of the poetic sense. It seeks, therefore, to demonstrate the contributions of historical and dialectical materialism to teaching practice and human development. The theorists considerations allow us to note that language contributes to the development of higher psychic functions in man and the alienation of subjects in today's society considerably affects the students interpretation and, consequently, formation for critical reading, which can be overcome with the use of a conscious theoretical current.

KEY WORDS: Alienation. Language. Critical reading.

\section{Introdução}

As dificuldades apresentadas pelos alunos no momento da leitura, interpretação de textos, produção escrita, muitas vezes vão além da apropriação do código linguístico e do entendimento da gramática. As mazelas da leitura superficial podem estar relacionadas à alienação vivenciada pelos discentes diante de uma sociedade carente da formação integral, do ensino que abarca o conhecimento científico em sua totalidade, uma vez que este tipo de aprendizado é significativo ao aluno. No intuito de conhecer acerca da problemática e

RPGE - Revista on line de Política e Gestão Educacional, v Araraquara, v.21, n. esp.3, p. 1703-1714, dez., 2017. 
demonstrar o projeto de intervenção utilizado para saná-la, o artigo foi dividido em duas partes, sendo elas: a alienação na visão marxista e o processo histórico de formação do conceito mediante a visão dos teóricos desta corrente de pensamento. A segunda parte busca formas de superação da alienação do homem para o desenvolvimento do pensamento e da linguagem, no qual são expressas as atividades propostas e os resultados obtidos com a intervenção para a desmistificação do termo herói, dentre elas o uso do celular como instrumento pedagógico.

\section{A alienação na visão marxista}

Com o advento do capitalismo, o modo de produção sofreu uma profunda transformação, na qual as relações de trabalho, que até então tinham como base a produção manual passaram à manufatura. Desta maneira, o trabalhador perdeu o domínio da produção, pois ela não tinha mais o objetivo de suprir as necessidades de sobrevivência do homem, mas garantir o lucro do dono dos bens de capital. Na transformação do modo de produção, o trabalhador desvinculou-se do ato global produtivo no qual tinha o conhecimento completo do objeto. Além da perda do conhecimento, o poder aquisitivo do trabalhador reduziu-se. Com a remuneração descendente, o trabalhador dedica mais horas de labor para garantir a sobrevivência. Percebe-se nesse novo processo produtivo que o trabalhador ficou submisso ao objeto que produz.

A categoria alienação se encontra em posição central no marxismo, especificamente, na obra de Marx Os manuscritos econômicos e filosóficos de 1844, pois possibilita a elaboração de conceitos fundamentais referentes aos produtos da atividade humana, tais como: valor, mão-de-obra, mais-valia. Na origem da conceituação da palavra alienação, observa-se o caráter abstrato que o conceito assume em Hegel e Feuerbach, que se diferem pelo fato de Hegel ter como sujeito o espírito e Feuerbach o homem. No entanto, para Sánchez Vásquez (2011), Marx desenvolve o conceito de alienação a partir de Feuerbach, sendo as divergências e convergências tais pontos: Para Feuerbach o sujeito que se aliena é o homem, para Marx é o trabalhador; o caráter da atividade da alienação em Feuerbach é teórico, em Marx é prático; o produto desta atividade para Feuerbach é o objeto ideal: Deus, para Marx é o objeto real: o produto do trabalho; a esfera da alienação para Feuerbach é a consciência humana, para Marx é o trabalho humano; o conteúdo da alienação em Fuerbach é a desumanização do homem, para Marx é a desumanização do

RPGE - Revista on line de Política e Gestão Educacional, v Araraquara, v.21, n. esp.3, p. 1703-1714, dez., 2017. 
trabalhador; o que se aliena e desaliena em Feuerbach coincide com o pensamento de Marx: a essência humana. (SÁNCHEZ VÁSQUEZ, 2011).

Vale ressaltar que para Feuerbach, a alienação ocorre no homem em geral, como uma necessidade antropológica, constitutiva do ser. Em Marx, a alienação se desenvolve a partir das razões históricas e sociais, nas quais o trabalhador aliena sua essência nas relações práticas. Marx em os Manuscritos de 1844 considera a alienação: como fato econômico, já que a categoria influencia e explica a divisão de classes (empobrecimento de um classe em contraponto ao enriquecimento da outra); o trabalho como algo externo ao homem (o homem não se identifica com o objeto que produz); atitude subjetiva em relação aos outros homens (relações sociais distantes entre os homens), mesmo que nesta obra, Marx ainda considera a alienação a partir das características subjetivas. No entanto, em O Capital, nota-se que a alienação passa a ser tratada objetivamente, pois está mais relacionada com o conceito aprofundado de trabalho, do qual se constitui no processo prático de transformação do material de acordo com as intencionalidades de sanar as necessidades humanas.

A partir de $O$ Capital, a alienação se subordina ao concreto e ao objetivo, mais especificamente à divisão social do trabalho. Nesta obra, ocorre a concretização de uma teoria do trabalho humano e de seus produtos condicionados pelos fatores históricos no modo de produção capitalista. Por isso, a alienação é exposta como a coisificação na qual estão submetidas as relações sociais e de produção dos homens, no resultado do fetichismo do objeto (mercadoria, dinheiro e capital), que podem afetar a dignidade humana. Nos Manuscritos de 1844, a alienação estava relacionada à relação sujeito-objeto, ou seja, à realização do trabalho concreto. Em $O$ Capital, Marx vincula alienação às relações sociais de produção e ao objeto. Em ambas as obras, a objetivação é autônoma, no entanto, em $O$ Capital, além de autônoma é fruto das relações sociais. Em suma, “[...] se no primeiro caso o produto o trabalho faz do sujeito um objeto ao que domina, no segundo a mercadoria coisifica uma relação social”. (SÁNCHEZ VÁSQUEZ, 2011, p. 433).

A educação para além do capital preconizada por Mészáros (2007) reivindica o ensino que revele as intencionalidades do sistema capitalista, que atue com a alienação dos sujeitos em diferentes instâncias: política, econômica, social, sendo o Estado um dos seus principais mediadores, pois contribui para a disseminação de discursos repletos do desejo de apenas corrigir o sistema atual vigente para que este se perpetue. No entanto, o estudioso vê a necessidade de uma transformação social, ampla e emancipadora do homem 
que passa pela educação e pelo trabalho. Para isso, faz-se necessário interferir no processo de internalização utilizados pelos donos do capital, pelos diversos meios de comunicação, que atua como forma de manutenção do status quo. (MÉSZÁROS, 2007). Observa-se no processo de internalização que os donos do capital buscam manter a alienação das relações sociais, de modo a promover o processo conforme as intencionalidades da classe dominante.

Nota-se que diferentemente do animal, o homem pode representar a realidade cognitivamente. Nesse processo, as palavras assumem significativa importância, já que representam os signos que compõem o ato, o objeto, o fenômeno. Dessa forma, a linguagem representa o elo entre o fazer humano e o conhecimento, transmitindo entre as gerações as apropriações de forma a superar as condições impostas anteriormente, seria o agir consciente. De acordo com estudos psicológicos de Leontiev (2001), esmiuçados no livro Desenvolvimento do psiquismo, graças à linguagem, o homem é capaz de compartilhar o pensamento, e por isso, contribui para a organização e sistematização da atividade humana. No entanto, o desenvolvimento humano fica limitado quando o processo do conhecimento, que é histórico e por isso dinâmico, encontra-se alienado. O resultado seria a fetichização dos indivíduos e de suas relações. Nessa condição as relações advindas com o trabalho se transformam em coisas, mercadorias nas quais se estabelecem valores e não o inverso. Por isso, a deformação das propriedades essenciais dos seres humanos, o trabalho, resultam no esvaziamento dos valores, o desmantelamento desta realidade estaria na formação humana de “[...] sujeitos ativos, capazes de dar direção à vida para além dos estritos limites do individualismo". (MARTINS, 2004, p. 63).

\section{As contribuições da linguagem para a formação do homem}

A linguagem se constitui como signo pelo qual o homem transmite aos seus semelhantes, historicamente, o conhecimento. No entanto, faz-se necessário conhecer o processo de desenvolvimento da linguagem, considerada essencial para a superação biológica do homem em relação aos outros animais. Os primeiros indícios da linguagem surgem com o desenho, uma forma precoce que posteriormente levará à escrita. Pelo desenho, a criança começa a expressar suas percepções acerca de assuntos relacionados à rotina. $\mathrm{O}$ grande salto qualitativo surge quando a criança descobre que pode representar a fala do adulto com o uso dos signos. (VIGOTSKI, 2010). A linguagem se aprimora a partir

RPGE - Revista on line de Política e Gestão Educacional, v Araraquara, v.21, n. esp.3, p. 1703-1714, dez., 2017. 
dos fatores biológicos, que são superados pelos fatores sociais, ou seja, nas relações sociais a criança se desenvolve de forma a melhorar significativamente os conceitos apropriados no contexto que vive. A cada novo contato com o objeto a criança se apropria de mais conhecimento, que permite ao homem penetrar na essência das coisas. Cabe ressaltar que a palavra cumpre a função que vai além da representação. Pode-se considerar que ela é a célula do pensamento ao abstrair e generalizar o objeto. (LURIA, 1987). Nesse sentido, a palavra é complexa, pois essa referência objetal está envolta num campo semântico permeado por significados. Assim, considera-se que a palavra possibilita ao homem ir além da percepção imediata para apropriação racional do signo, sendo esta a essência da consciência humana.

O desenvolvimento dos conceitos pelos homens seguem dois caminhos: ascendente (quando parte do particular para o geral) e descendente (quando provenientes do geral para o particular). No ascendente, o sujeito nas relações sociais desenvolvem conceitos comuns, cotidianos ou espontâneos, processo empírico de contato imediato com o objeto, que em grande parte se faz de forma inconsciente. No entanto, estes conceitos podem ser superados com a apropriação dos conceitos científicos, com o entendimento da totalidade que os envolvem. Já no descendente, o processo organizado e sistematizado do ambiente escolar, envolve os sujeitos de forma consciente de todas as ramificações que envolvem o objeto, fato ou fenômeno. Dessa maneira, as operações mentais mais complexas podem interagir com os conceitos cotidianos, sendo essas ações conscientes e compreendidas pelos homens. Neste movimento, o sujeito passa a compreender o mundo e as relações nele existentes. (VIGOTSKI, 2002). Observa-se que a aprendizagem necessita antecipar-se ao desenvolvimento para que seja propulsora do desenvolvimento humano, ou seja, no trabalho escolar que vá além dos conhecimentos cotidianos, o aprendizado precisa proporcionar ações mentais complexas para a apropriação do saber. Este tipo de aprendizagem permite ao homem conhecer a essência do objeto e não apenas a aparência, libertando-os das percepções sensoriais, das visualizações de traços comuns. Segundo Duarte (2003) a metáfora utilizada por Marx, a anatomia do homem é chave da anatomia do macaco, serve para explicar a importância do entendimento da totalidade do objeto, ou seja, significa partir da fase mais desenvolvida do objeto, para a sua gênese, sua essência, para depois retornar ao ponto de partida de uma forma compreendida em todas as interrelações que o compõe pela análise histórica. 
Para tanto, nota-se a importância da mediação docente no processo de aprendizagem. Nesse processo, o professor se constitui o elo entre o aluno e o conhecimento, de forma a entrelaçar o conteúdo a ser trabalhado com as várias dimensões na qual o objeto está relacionado para a total compreensão e depois o uso consciente do conhecimento. Com esse pensamento, Vigotski (2010) desenvolveu o que denominou de Zona de Desenvolvimento Proximal - ZPD - processo descrito no livro Pensamento e Linguagem do psicólogo russo, no qual o aluno é exposto a desafios de aprendizagem que estão acima dos considerados para a idade biológica com o auxílio de um mediador (adulto ou pessoa com mais conhecimento que o estudante) fazendo-o adiantar-se em seu desenvolvimento, ou seja, trabalha-se com o desenvolvimento iminente, com ações que possuem dificuldades maiores do que antes lhe eram solicitadas. (MARTINS, MARSIGLIA, 2015). Considera-se que ao recorrer a base teórica do materialismo histórico e dialético como fundamento para os planejamentos escolares, o professor afugenta-se do construtivismo, no qual as experiências dos discentes estavam relacionadas ao uso restrito da prática, do empirismo e respaldadas pelo desenvolvimento dividido por fases.

Para o desenvolvimento do ensino se faz essencial a linguagem que contribui significamente para o desenvolvimento das funções psíquicas superiores. Essas funções possibilitam diferenciar o homem dos outros animais ao superar ações imediatistas atreladas ao campo biológico. À medida que o ser humano desenvolve ações voluntárias de atenção, memória mediada, por exemplo, ele passa a se distinguir dos outros animais. Nesse processo, a linguagem se torna essencial. Como já citado anteriormente, a linguagem escrita surge quando o homem percebe que pode desenhar a fala. No entanto, esse registro não está desvinculado de um contexto maior, histórico e social de uma comunidade, no qual as intencionalidades estão presentes. Com a linguagem, o homem realiza não somente a troca de conhecimentos sobre determinado objeto, mas também de pensamentos. (MARTINS, 2004). O papel da linguagem na organização do ativo voluntário advém da comunicação da criança com o adulto. Começa com o ato prático, quando a criança obedece as indicações do adulto, para depois utilizar-se da linguagem externa em consonância com a ação. $O$ ápice surge no momento que a fala interioriza-se. Ao transformar em linguagem interna surge a regulação voluntária consciente da criança, que foi mediada pela linguagem. Nota-se que a linguagem assume papel principal na mudança de conduta da criança ao desenvolver as ações que a princípio se mostravam 
involuntárias para voluntárias. Isso ocorre devido a organização que a linguagem proporciona ao pensamento. (LURIA, 1987).

\section{Desenvolvimento da leitura crítica em sala de aula}

As atividades foram desenvolvidas com cerca de 60 alunos, sendo eles divididos em duas turmas de $7^{\circ}$ ano escolar de uma escola pública. $\mathrm{O}$ docente juntamente com os estudantes haviam trabalhado a temática heróis nas aulas anteriores. No entanto, o tema foi embasado no conceito de herói fictício nos gêneros discursivos: relatos, contos de mitologia. Sendo assim, a temática herói foi selecionada juntamente com o conteúdo previsto para o segundo bimestre letivo, o gênero poesia, mais especificamente o poema haicai. Sabendo da importância do trabalho com os conteúdos e a necessidade de mediar o conhecimento dos alunos com o uso de formas diferentes, para expressar o saber apropriado, juntou-se o ensino do poema haicai que em seu cerne está a expressividade da imagem juntamente com a poesia, em consonância com a desconstrução do conceito de herói, para que ao final os alunos pudessem ter consciência que o conceito do termo herói é mais abrangente do que o estudado até o momento, pois expressa o ser humano que pratica ações de coragem, ou ainda, sujeito que age mediante atos extraordinários com sentimento de bondade.

Para tanto, as aulas partiram do geral, dos conhecimentos dos estudantes, para o particular, na busca pelo aprofundamento do conceito, para então retornar ao geral consciente, como o próprio movimento do conhecimento descrito por Marx (1978) quando se refere a forma de análise de um país no livro $O$ Capital. Neste movimento, o aluno passa a ter uma visão de totalidade de inter-relações na qual o conceito está imerso. Com o uso da dialética, algumas questões foram formuladas para compreender qual o conceito dos alunos de herói. A partir dessa análise preliminar, outras questões foram levantadas de forma a problematizar o termo e trazer para a realidade brasileira a questão do herói. Notase a necessidade de internalizar o conhecimento dos estudantes, que se encontra muito superficial, como nos alerta Mészáros (2007) ao embasar-se no materialismo como forma de superação da exploração do capital. Segundo o estudioso, a educação pode contribuir tanto para disseminar intencionalidades de dominação, como para formar sujeitos conscientes de sua realidade. 
Ao buscar transformar o conhecimento em-si para conhecimento para-si, no processo de internalização, como denominado por Duarte (2003), o homem mediante as relações sociais entram em contato com o saber que após compreendido e estudado em sua totalidade passa a fazer parte da sua consciência. Esse estudioso, defensor da Pedagogia Histórico-Crítica como corrente a levar o aluno à apropriação dos conteúdos científicos, esclarece em um de seus textos do livro Sociedade do conhecimento ou sociedade das ilusões, que a chave para o conhecimento está em compreender como funcionam os sistemas superiores de um objeto. Para isso, o educador cita a metáfora de Marx, mencionada anteriormente, na qual Vigotski (2002) busca no marxismo a base para uma psicologia geral. Considera o método dialético do marxismo como ponto crucial para o entendimento das contradições presentes na sociedade, assim como para o desenvolvimento do homem. As mediações que seguiram foram consubstanciadas pelo ensino consciente do termo herói e o uso de algumas personalidades brasileiras consideradas heroínas pela nossa sociedade, tais como: Zumbi dos Palmares; Ayrton Senna; Cândido Portinari; cada qual com suas especificidades foram trabalhados a partir do histórico de atuação; num entrelace entre o conceito de herói e as contribuições dos mesmos para a sociedade de forma que fossem considerados heróis. A partir dessa fonte concreta de sujeitos, os estudantes puderam perceber que existem heróis mais próximos da realidade vivenciada por todos. A importância do trabalho com o concreto, com o material para Saviani (2011) se constitui a base para o desenvolvimento do conhecimento. De acordo com o educador que formulou a Pedagogia Histórico-Crítica, que possui seu cerne no materialismo histórico e dialético, o movimento do conhecimento parte do concreto (conhecimento ainda caótico, disperso, de senso comum) para o abstrato (aprofundamento das várias inter-relações do objeto, fato ou fenômeno), para consolidar-se no concreto pensado (momento de síntese do conhecimento, organizado, elaborado). Portanto, nota-se que esse processo é contínuo e se repete em forma de espiral a cada nova assimilação do aluno, a cada nova aprendizagem consciente.

No caso das aulas desenvolvidas com os alunos, o docente partiu do conhecimento unilateral do termo herói para ampliar os estudos sobre o conceito, de forma a abranger as especificidades que a palavra possui, integrando ao significado o histórico de algumas personalidades brasileiras consideradas heroínas, e aproximando a arte e a poesia, a vivência dos estudantes. Para tanto, o material trabalhado trazia imagens das personalidades estudadas, textos com o histórico, vídeos ilustrativos, além de manter um

RPGE - Revista on line de Política e Gestão Educacional, v Araraquara, v.21, n. esp.3, p. 1703-1714, dez., 2017. 
diálogo constante entre o docente e o aluno ao indagar sobre o que estava sendo aprendido e relacionado com a realidade vivenciada. Desta maneira, buscava-se a dialética das contradições presentes entre o conceito fictício e a realidade dinâmica e concreta dos estudantes. Percebe-se que o processo de ensino e aprendizagem nessa linha teórica proporciona a apreensão dos conteúdos de forma significativa e com sentindo. Vale lembrar que para Vigotski (2011), o ensino significativo ao aluno é aquele no qual percebe sentido em seu uso, ou seja, o aluno vai aprender a ler à medida que sentir necessidade de ler. No entanto, essa necessidade precisa ser desenvolvida pelo docente em sala de aula, por isso a importância do papel de mediador do docente no materialismo histórico e dialético e a organização e sistematização do ensino realizada por ele. Com isto, entende-se que significativo é aquilo que se torna interessante ao aluno frente a mediação do outro, na escola, realizada pelo professor, e na sociedade pelas relações sociais.

A diferença entre significativo e sentido estaria na importância que uma temática possui para o aluno e sentido seria o entendimento das inter-relações que o objeto, fato ou fenômeno possui nas diferentes dimensões do qual faz parte, tais como: sociais, econômicas, culturais, étnicas, políticas. Observou-se nas aulas que os alunos desconheciam grande parte dos heróis nacionais estudados. No entanto, demonstraram interesse em conhecer e relacionar com o conceito e as atividades que realizaram para serem denominados heróis. Nesse caminhar, puderam ter a oportunidade de conhecer obras de arte como "O Café" e a "Seca" de Cândido Portinari, os poemas de Helena Kolody, que podem ser considerados como uma cultura mais elevada, sendo essa uma função de suma importância da escola. O conhecimento consciente de tais obras foi apropriado mediante a dialética do docente e os alunos mediados pela visualização de imagens, leitura de poemas, vídeos explicativos. Para Martins (2004), a transformação do ser ocorre quando o corpo passa de uma dependência orgânica para a inorgânica. No caso, dos alunos participantes, quando a poesia passou a fazer parte dos olhares e sentimentos do envolto escolar. Nesse caso específico, os alunos retrataram a escola com fotos, e buscaram em cada ambiente observar objetos, seres, fenômenos que pudessem provocar um sentimento, uma estranheza que depois seria descrita em forma de poema, em forma de síntese. Para tanto, a atividade de fotografia com o uso do celular organizada pela docente e realizada junto com os alunos na escola foi fundamental para o desenvolvimento do senso poético. A escola possui uma área grande, com muitas árvores, gramados, plantas e pequenos animais, que muitas vezes passa despercebida pelos estudantes. Quando convidados para realizar fotos que pudessem 
ser transformadas em poemas, os alunos com o saber da estrutura do haicai, buscaram imagens que depois seriam transpostas para a linguagem escrita, de forma que o leitor pudesse visualizar aquele momento e em seguida captar o sentido de mudança e síntese da intenção de cada estudante em registrar o momento. Dessa forma, o instrumento celular, muito mais acessível aos alunos, pode ser utilizada para captar formigas trabalhando, nuances diferenciadas de folhagens, árvores robustas, árvores com frutos da estação, coloração do sol, formado das nuvens. As imagens foram compartilhadas por meio do aplicativo whatsapp e depois transformadas em exposição pela professora, na aula seguinte, no intuito de demonstrar os diferentes olhares dos estudantes para o mesmo objeto.

A finalização dos trabalhos desenvolvidos com os alunos foi a produção de dois haicais, sendo um com a temática herói e outro de temática livre. Nessa atividade, os alunos buscaram entrelaçar o conteúdo e a forma. As imagens consideradas mais significativas aos estudantes foram transcritas na estrutura geral do poema haicai, juntamente com as principais temáticas, tais como: natureza, animais, estações do ano. As sessenta produções expressaram em forma de síntese a mensagem principal dos alunos ao conteúdo trabalhado em sala de aula, que depois foi socializado de duas formas: um sarau de poesias entre os participantes e o varal de poemas expostos para os demais alunos do colégio. Percebe-se que os alunos compreenderam o conteúdo poema, especificamente a construção do haicai, como também o conceito mais amplo da palavra herói. O ensino pautado nessa corrente de pensamento possibilitou um aprendizado consciente, sem a necessidade de memorizações momentâneas, ou ainda, reproduções inconsciente de materiais.

\section{Considerações finais}

Percebe-se que o desenvolvimento humano ocorre na superação das condições biológicas, instintivas, que contribuem em suma para a manutenção do ser diante de algumas situações de perigo. No entanto, elas são insuficientes para explicar o salto evolutivo do homem enquanto sujeito que age mediante abstrações e generalizações, que são fundamentais para a criação e uso dos instrumentos. Nesse contexto, observa-se a importância da atividade humana para o intercâmbio de conhecimento, assim como para o surgimento de novas necessidades diante da natureza e ou das relações sociais. No intuito

RPGE - Revista on line de Política e Gestão Educacional, v Araraquara, v.21, n. esp.3, p. 1703-1714, dez., 2017. 
de controlar o homem, a sociedade capitalista busca na alienação um modo de internalizar discursos, conduzir atitudes para que não haja discordâncias do sistema de exploração, no qual poucos se beneficiam dos lucros e do bem estar econômico. A contrapelo das medidas de dominação está o materialismo histórico e dialético que pressupõe como primazia a leitura crítica dos discursos. Entretanto, é preciso conhecer a teoria e entender os pressupostos da mesma, assim como aprofundar-se dos conceitos que são a base para o entendimento, tais como: alienação, linguagem, para que o docente em sala de aula seja o mediador do aluno na apropriação da totalidade de conhecimentos de um conteúdo. Somente, desta forma, o aluno poderá realizar a leitura crítica da sociedade da qual faz parte e entender o seu papel como cidadão.

O trabalho em sala de aula não pode estar desvinculado das necessidades sociais dos alunos, no entanto, precisa ser aprofundado para que seja científico, como também direcionado para os conteúdos escolares básicos. O docente necessita estar atento a principal função da escola que é disseminar o conhecimento historicamente acumulado pelo homem, para que tenha sentido ter a instituição de ensino, caso contrário o senso comum seria predominante prejudicando o desenvolvimento do homem. Para conciliar essas necessidades, ensino significativo e conteúdo escolar, percebe-se a importância de pautar-se em uma linha teórica como o materialismo histórico e dialético, o movimento do conhecimento expresso pelos teóricos que o apoiam realmente está presente quando se parte do geral para o particular e volta-se ao geral de forma consciente. Pode-se considerar que a princípio é mais oneroso o trabalho com essa corrente, porque não existe algo pronto como as demais. No entanto, o trabalho final transforma o aluno, o docente, a escola, sendo esse processo contínuo e estimulante. Os alunos participantes puderam compreender o conceito em consonância com o poema de maneira a transformar seus olhares para outras situações, porque o ensino teve sentido e significado, sendo assim possível transpor o aprendizado para outras situações. Desta forma, nota-se que essa corrente de processo de ensino-aprendizagem se torna uma possibilidade consciente de trabalho a ser desenvolvido em diferentes anos escolares.

AGRADECIMENTOS: OBEDUC- UEL

\section{REFERÊNCIAS}

RPGE - Revista on line de Política e Gestão Educacional, v Araraquara, v.21, n. esp.3, p. 1703-1714, dez., 2017. 
DUARTE, Newton. Sociedade do conhecimento ou sociedade das ilusões? Quatro ensaios críticos-dialéticos em filosofia da educação. Campinas, SP: Autores Associados, 2003.

LEONTIEV, Alexei. O desenvolvimento do psiquismo. Tradução Manuel Dias Duarte. Cascavel, PR: Livros Horizonte. Centro de confecção de material em braile. Julho, 2001.

LURIA, Alexander Romanovich. Pensamento e linguagem: as últimas conferências de Luria. Porto Alegre: Artes Médicas, 1987.

MARTINS, Ligia Márcia. Da formação humana em Marx à crítica da pedagogia das competências. In: DUARTE, Newton (org). Crítica ao fetichismo da individualidade. Campinas, SP: Autores Associados, 2004.

MARTINS, Ligia Márcia.; MARSIGLIA, Ana Carolina Galvão. As perspectivas construtivista e histórico-crítica sobre o desenvolvimento da escrita. Campinas, SP: Autores Associados, 2015.

MARX, Karl. Manuscritos econômico-filosóficos e outros textos escolhidos. In: Marx. São Paulo, Abril Cultural (coleção Os pensadores). 1978.

MÉSZÁROS, István. O desafio e o fardo do tempo histórico: o socialismo no século XXI. Tradução Ana Cotrim, Vera Cotrim. São Paulo: Boitempo, 2007.

SÁNCHEZ VÁSQUEZ, Adolfo. Filosofia da práxis. $2^{a}$ ed. Tradução María Encanarción Moya. São Paulo: Expressão Popular, 2011.

SAVIANI, Dermeval. Educação socialista, pedagogia histórico-crítica e os desafios da sociedade de classes. In: LOMBARDI, José Claudinei.; SAVIANI, Dermeval (Org). Marxismo e educação: debates contemporâneos. Campinas, SP: Autores Associados: HISTEDBR, 2005, p. 224-274.

SAVIANI, Dermeval. Pedagogia histórico-crítica: primeiras aproximações. 11 ed. ver. Campinas, SP: Autores Associados, 2011.

VIGOTSKI, Lev Semenovitch. Formação Social da mente. São Paulo, SP: Martins Editora, 2010.

VIGOTSKI. Pensamento e Linguagem. eBooksBrasil, 2002. Edição eletrônica: Ed Ridendo Castigat Mores. Disponível em: http: <www.jahr.org>. Acesso em: 10 mar. 2015.

\section{Como citar este artigo}

GALVÃO, Rosangela Miola.; FRANCO, Sandra Aparecida Pires. Superação da alienação dos alunos para a realização da leitura crítica. Revista on line de Política e Gestão Educacional, Araraquara, v.21, n. esp.3, p. 1703-1714, dez., 2017. ISSN: 1519-9029. 